\title{
Preparation, Characterization and in Vitro Evaluation of the Antitumor Activity of the Biologically Synthesized Silver Nanoparticles
}

\author{
Omama E. Elshawy ${ }^{*}$, Eman A. Helmy², Laila A. Rashed ${ }^{3}$ \\ ${ }^{1}$ Health Radiation Research Department, National Centre for Radiation Research and Technology (NCRRT), \\ Atomic Energy Authority (AEA), Cairo, Egypt \\ ${ }^{2}$ Regional Centre of Mycology and Biotechnology (RCMB), Al-Azhar University, Cairo, Egypt \\ ${ }^{3}$ Medical Biochemistry Department, Faculty of Medicine, Cairo University, Cairo, Egypt \\ Email: "dromaymaelshawi@hotmail.com
}

Received 14 March 2016; accepted 27 May 2016; published 30 May 2016

Copyright $@ 2016$ by authors and Scientific Research Publishing Inc.

This work is licensed under the Creative Commons Attribution International License (CC BY). http://creativecommons.org/licenses/by/4.0/

(c)

\section{Abstract}

This study was concentrated on the biosynthesis of silver nanoparticles from Penicillium aurantiogresium (IMI 89372) with a focus on its cytotoxicity in MCF-7 and MCT cancer cell lines as well as Vero (normal) cell line that was assessed by crystal violet assay after treatment with various concentrations $(0.44-145 \mu \mathrm{g} / \mathrm{ml})$ for $24 \mathrm{~h}$. The cell morphology was examined by inverted light microscopy. Further, the radiosensitizing effect of silver nanoparticles (AgNPs) on MCF-7 was also demonstrated by assessing cell morphology, cell proliferation of MTT assay, LDH activity and induction of apoptosis through checking of some apoptotic genes that altered during carcinogenesis, including caspase-3, Bax and Bcl-2. Caspase-3 activity was also estimated. Synthesis of AgNPs was determined by UV-Visible spectrum and it was further characterized by TEM, FT-IR and X-Ray analysis (EDX, XRD). The biosynthesized AgNPs were spherical and of $12.7 \mathrm{~nm}$ in size as recorded by direct electron microscopy visualization. The biosynthesized AgNPs showed variation in cytotoxicity against MCF-7, MCT and Vero cell lines in a concentration dependant response with a varied degree of alteration in cell morphology. The result showed that AgNPs were highly toxic towards MCF-7 with IC50 value of $10.5 \mu \mathrm{g} / \mathrm{ml}$. Treatment of MCF-7 $(10.5 \mu \mathrm{g} / \mathrm{ml})$ prior to irradiation improved the effect of irradiation dose ( $6 \mathrm{~Gy}$ ) via increasing alteration of cell morphology, inhibition of cell proliferation, activation of the lactate dehydrogenase (LDH) and caspase-3 leading to induction of apoptosis which was further confirmed through increasing nuclear DNA damage and up regulation of caspase 3 and Bax genes and downrgulation of Bcl-2 genes. In conclusion, the present findings clearly indicated that AgNPs showed dose dependant cytotoxicity and verified

\footnotetext{
${ }^{*}$ Corresponding author.
} 
that AgNPs acted as a potent radiosensitizer and could enhance gamma irradiation induced killing of MCF-7 breast cancer cells.

\author{
Keywords
}

Penicillium aurantiogriseum, Silver Nanoparticles, in Vitro, Cytotoxicity, Radio-Sensitivity

\title{
1. Introduction
}

Numerous complications are associated with the use of conventional anticancer drugs, including insolubility in water, rapid clearance, and lack of selectivity, resulting in non-specific toxicity regarding normal cells and insufficient dose of drug delivered to the cancer cells [1].

Nanobiotechnology is the most promising field for generating new kinds of nanomaterials for biomedical applications [2]. Because nano-particles (NPs) have the affinity to an acidic environment, which characterized tumor tissue, it is believed that selective targeting strategies with NPs facilitate more effective cancer detection and treatment with minimized side effects to normal cells [1].

Various natural resources have been used for green synthesis of NPs: plants, plant products, bacteria, fungi, algae, yeast, and viruses [3]. The most commonly preferred method is using bacteria or fungi due to the fact that they are easy to handle, and the possible genetic manipulation [4].

"Green synthesis" of nanoparticles makes use of environmental friendly, non-toxic and safe [5]. Silver nanoparticles are of particular interest for applications in medical devices and healthcare products because of their antibacterial activity and low toxicity to human cells.

AgNPs have gained much interest in the field of nanomedicine due to their unique properties and obvious therapeutic potential in treating a variety of diseases [6] and have a great potential in cancer management because they have selectivity involved in disruption of mitochondrial respiratory chain leading to the production of reactive oxygen species (ROS), induced the expression of genes associated with DNA damage, and enhanced apoptosis of tumor cells [7]. AgNPs induce cell damage in a dose- and size-dependent manner; a higher dose and a smaller size lead to increased cytotoxic effects [8].

On the basis of the aforementioned, this study was designed to assess the cytotoxicity of the mycosynthesized AgNPs in MCF-7, HCT human cancer cells as well as the non-cancerous (Vero) normal cells. We also attempt to provide concentrated insight into AgNPs as a radio sensitizing agent.

\section{Materials and Methods}

\subsection{Microorganisms}

The Fungal type of Penicillium aurantiogresium (IMI 89372) strain used in this study and was kindly provided by the culture collection unit of the Regional Centre for Mycology and Biotechnology (RCMB), Al-Azhar University, Cairo, Egypt. The culture strain was maintained and sub cultured on malt extract agar (MEA) slants and plates containing; 20gm malt extract; 20 gm glucose; 1 gm peptone; 20 gm agar (Ingredients in one litre of distilled water).

\subsection{Biomass Production and Biosynthesis of Silver Nanoparticles}

The biomass of biosynthesized AgNPs was prepared previously [9]. In brief, the fungus was grown aerobically in a liquid medium containing (g/l) $\mathrm{KH}_{2} \mathrm{PO}_{4}-7.0 ; \mathrm{K}_{2} \mathrm{HPO}_{4}-2.0 ; \mathrm{MgSO}_{4}-0.1 ;\left(\mathrm{NH}_{4}\right)_{2} \mathrm{SO}_{4}-1.0$; yeast extract-0.6; and glucose-10.0 ( $\mathrm{pH}: 6.2 \pm 0.2$ ). The flasks were inoculated and incubated on orbital shaker at $25^{\circ} \mathrm{C}$ and agitated at $150 \mathrm{rpm}$. The biomass were harvested after 72 hours of growth by sieving through Whatmann filter paper No.1 followed by extensive washing with distilled water to remove any undesired component from the biomass.

To prepare extracellular fungal cell-free extract for the synthesis of AgNPs, $20 \mathrm{~g}$ of fresh, clean fungal biomass was brought in contact with $100 \mathrm{ml}$ of de-ionized water in an Erlenmeyer flask and incubated at $25^{\circ} \mathrm{C}$ in dark shaking incubator (150 rpm) for 72 hours. After incubation, the cell filtrate was obtained by passing it 
through Whatmann filter paper no.1. For synthesis of silver nanoparticles, $50 \mathrm{ml} \mathrm{AgNO}_{3}(1 \mathrm{mM})$ was mixed with $50 \mathrm{ml}$ of extracellular fungal cell-free extract in a $250 \mathrm{ml}$ Erlenmeyer flask and agitated at $25^{\circ} \mathrm{C}$ and $\mathrm{pH} 4.0$ in the dark shaking incubator at 150 rpm for 72 hours. Two controls were used; first negative control containing only biomass without the silver ion, and second positive control containing $1 \mathrm{mM} \mathrm{AgNO}_{3}$ that run along with the experimental flasks.

The formation of silver nanoparticles was detected by turning the color of the mixture after incubation from light yellow to dark reddish brown. The reduction of silver ions was confirmed by qualitative testing of the supernatant by UV-visible spectrophotometer (Spectronic Milton Roy $1201 \mathrm{UV}$ ). $1 \mathrm{mM}$ of $\mathrm{AgNO}_{3}$ was mixed with $50 \mathrm{ml}$ of the cell filtrate in a $250 \mathrm{ml}$ Erlenmeyer flask at $25^{\circ} \mathrm{C}$ and $\mathrm{pH} 4$ and agitated in the dark. Optical density was measured each 10 min starting of incubation until 72 hours and at different wavelength ranging from 200 to $800 \mathrm{~nm}$ and plotted the values on a graph.

\subsection{Characterization of the Biosynthesized Silver Nanoparticles (AgNPs)}

The characterization of silver nanoparticles was carried out according to Helmy and Mekawy (2013) using different instruments and techniques including visual observation, UV-Visible spectrophotometer, X-ray diffraction (XRD) of TEM, energy-dispersive X-ray (EDX) of SEM, Fourier transform infra-red (FT-IR) analysis and TEM.

\subsubsection{UV-Visible Spectroscopy}

The UV-Visible spectrophotometer has proved to be a very useful technique for the analysis of some metal nanoparticles and is a significant technique to authenticate the formation and stability of AgNPs in aqueous solution.

\subsubsection{Transmission Electron Microscopy (TEM) and X-Ray Diffraction Analysis}

Silver nanoparticles (AgNPs) size diameter and shape were reported and determined by Transmission Electron Microscopy (TEM JEOL 1010, Japan) and the crystalline AgNPs were determined by X-ray diffraction analysis using X-ray diffraction (XRD) of (XRD/TEM JEOL 1010, Japan). Samples for TEM were prepared by putting a drop of the AgNPs solution onto a conventional carbon coated copper TEM grid (400 meshes, Plano Gmbh, Germany), allowing the drop to dry overnight at room temperature before imaging. X-ray diffraction analyses as well as the TEM images of the samples were obtained using an accelerating voltage of $30 \mathrm{KV}$ and $80 \mathrm{KV}$, respectively. At least three images of each sample were taken to have a clear representation of its morphology.

\subsubsection{Scanning Electron Microscope (SEM) Analysis}

For SEM imaging, a sample of a solution was placed on a carbon strip attached to an SEM brass support and dried at $50^{\circ} \mathrm{C}$ for $5 \mathrm{~min}$. The energy-dispersive X-ray (EDX) spectra (SEM/EDX, JSM-5500 LV JEOL, SEM, Japan) were used to examine the dimension, morphology, and chemical composition of the samples. Surface binding elements were analyzed with X-ray photoelectron spectroscopy. Silver nanoparticle which was excited by an electron beam showed the peak values of Ag element.

\subsubsection{Fourier Transform Infra Red (FT-IR) Spectroscopy Analysis}

The infrared analysis of the nanoparticles was performed on a Fourier transform infrared (FT-IR) spectrometer (IRPrestige-21 ${ }^{\circledR}$, German) to understand the protein-nanoparticle interaction and to identify the possible biomolecules which are responsible for reduction of $\mathrm{Ag}^{+}$ion and capping of the bio-reduced nanoparticles synthesized by the fungal cells. Prior to analysis, the fungal filtrate containing nanoparticles was stirred at a speed of $5000 \mathrm{rpm}$ for $10 \mathrm{~min}$, and it was then washed with deionized water three times and air-dried. The dried samples were pressed into pellets. The sample pellets were placed into the sample holder and FT-IR spectra were recorded in the range of $450-4000 \mathrm{~cm}^{-1}$ at a resolution of $4 \mathrm{~cm}^{-1}$.

\subsection{Determination of Nanoparticle Concentration}

Accurate determination of the size and concentration of nanoparticles is essential for the biomedical application of nanoparticles and was determined according to the method previously reported [6]. The concentration of AgNPs to be administered at the level was determined by a method which has been previously reported. The 
calculation was as follows: Initially the average number of atoms per nanoparticles was calculated using the formula:

$$
\begin{aligned}
& N=\frac{\pi \rho D^{3}}{6 M} N_{A} \\
& N=\frac{\pi \times 10.5 \times\left(50 \times 10^{-7}\right)^{3} \times 6.023 \times 10^{23}}{6 \times 107.868}
\end{aligned}
$$

where $N=$ number of atoms per nanoparticle, $\pi=3.14, \rho=$ density of face-centered cubic silver $=10.5 \mathrm{~g} / \mathrm{cm}^{3}, D$ = average diameter of nanoparticles $=50 \mathrm{~nm}=50 \times 10^{-7} \mathrm{~cm}, M=$ atomic mass of silver $=107.868 \mathrm{~g}, N_{A}=$ number of atoms per mole (Avogadro's number $=6.023 \times 10^{23}$ ).

Therefore, assuming $100 \%$ conversion of all silver ions to silver nanoparticles:

i.e., $N=3837233.003$, then the molar concentration of the nanoparticle solution determined by

$$
N=\frac{1 \times 6.023 \times 10^{23}}{3837233.003 \times 1 \times 6.023 \times 10^{23}}
$$

where; $C$ =molar concentration of the nanoparticle solution, $N_{T}=$ total number of silver atoms added as $\mathrm{AgNO}_{3}$ $=1 \mathrm{M}, N$ =number of atoms per nanoparticle (from the calculation above), $V=$ volume of the reaction solution in $L, N_{A}=$ Avogadro's number $\left(6.023 \times 10^{23}\right)$.

The required concentrations were thereafter made up from the obtained values.

\subsection{Mammalian Cancer Cell Lines}

Colon (HCT), breast (MCF-7) human cancer cell lines, and Vero (normal cell lines) were obtained from the tissue culture unit of the Holding Company for Biological Products and Vaccines (VACSERA), Giza, Egypt and supplied through the American Type Culture Collection (ATCC).

\subsubsection{Subculture of Cell Lines}

Cultures were viewed using an inverted microscope to assess the degree of confluence and to confirm the absence of bacterial and fungal contaminants. Cell monolayer washed with PBS using a volume equivalent half of the volume of culture medium. Trypsin/EDTA was added on to the washed cell monolayer using $1 \mathrm{ml}$ per 25 $\mathrm{cm}^{2}$ of surface area. The flask was rotated to merge the monolayer with Trypsin/EDTA. The flask was returned to the incubator and left for 2 - 10 minutes. The cells were examined using an inverted microscope (CKX41; Olympus, Japan) to ensure that all the cells were detached and floated.

\subsubsection{Culture Media}

The cells were cultured in a humid environment at $37^{\circ} \mathrm{C}$ and $5 \% \mathrm{CO}_{2}$ atmosphere in RPMI-1640 medium supplemented with Penicillin (100 IU/ml), Streptomycin $(100 \mu \mathrm{g} / \mathrm{ml})$ and $10 \%$ fetal bovine serum.

\subsection{Irradiation Conditions}

In order to investigate the enhancement the radiosensitivity of MCF-7 cell lines, the cells were exposed to AgNPs at a concentration of $10.5 \mu \mathrm{g} / \mathrm{ml}$ for $24 \mathrm{hrs}$ then exposed to $6 \mathrm{~Gy}$ irradiation at a dose rate of $(0.657$ Gy/minute) in the Canadian Gamma Cell-40 (137Cs) at the National Centre for Radiation Research and Technology (Cairo, Egypt).

\subsection{Cytotoxicity Assay}

Crystal violet assay as described previously [10] was applied to demonstrate the viability of MCF-7, HCT and Vero cell lines under the effect of silver nanoparticles (AgNPs). Briefly, cells were plated in 96-well culture plates and exposed to various concentrations $(0.44,0.88,1.75,3.5,7.0$ and $14 \mu \mathrm{g} / \mathrm{ml})$ of AgNPs. In addition to control untreated cells. All cultures were incubated for 24 hours at $\left(37^{\circ} \mathrm{C}, 5 \% \mathrm{CO}_{2}\right.$ in a humid atmosphere) in a humidified incubator. At the end of the incubation period, the plates were inverted or aspirated to remove the medium. The wells were washed with $100 \mu \mathrm{l}$ of PBS. Finally, the dye was extracted from the cells by adding and mixing glacial acetic acid (33\%) to the contents of each well. The absorbance was measured in triplicates at 
$490 \mathrm{~nm}$ using ELISA Reader system (SunRise TECAN, Inc., USA). The cytotoxicity was evaluated as crystal violet reduction end point. The survival percentage was calculated as the ratio of the percentage optical density according to the following equation:

$$
\text { Survival\% }=\mathrm{OD}_{\text {treated }} / \mathrm{OD}_{\text {control }} \times 100 \text {. }
$$

The quantitative external morphology of exposed cells under the effect of AgNPs of $14 \mu \mathrm{g} / \mathrm{ml}$ concentration was analyzed using an inverted microscope (Leica, Germany) equipped with the digital microscopy camera to capture the images representing the morphological changes in MCF-7, MCT and Vero treated cell lines cells in relation to control cells.

\subsection{Enhancing the Radiosensitivity of MCF-7 by Mycosynthesized AgNPs}

The MCF-7 cell lines were selected to evaluate the potential effect of AgNPs to enhance the killing effect of radiotherapy. The cytotoxic activity of combined treatment with $\gamma$-ray irradiation and AgNPs in comparison to the cytotoxic effect of each treatment applied alone. Thus four sets of treatments were prepared. $1^{\text {st }}$ is the negative untreated MCF-7 cells, $2^{\text {nd }}$ is MCF-7 with $10.5 \mu \mathrm{g} / \mathrm{ml}$ AgNPs for $24 \mathrm{hrs} .3^{\text {rd }}$ group: cells was exposed to 6 Gy of gamma rays alone at a dose rate of $0.675 \mathrm{~Gy} / \mathrm{sec} .4^{\text {th }}$ group is the combined treatment, AgNPs was added to the cultures 24 hrs prior exposure to 6 Gy irradiation.

Cell morphology under the effect of different treatments was analyzed by the inverted microscopy as mentioned in the cytotoxicity set.

The radio sensitizing effect of AgNPs in MCF-7 cell lines was demonstrated in cellular and molecular levels via estimation of cell proliferation, membrane integrity (LDH assay), DNA fragmentation, caspase-3, Bax and Bcl-2.

\subsubsection{Cell Proliferation Assay}

Cell proliferation of MCF-7 cells of all groups was determined using the MTT (3-[4,5-dimethylthiazol-2-yl]-2.5diphenyl tetrazolium bromide) cell proliferation kit (Trevigen Inc., Gaithersburg, MD, USA) as per manufacturer's protocol. Briefly, cells were plated in 96-well tissue culture plates in a range of $10^{3}-10^{5}$ cells/well in the presence or absence of AgNPs $(10.5 \mu \mathrm{g} / \mathrm{ml})$ in a final volume of $100 \mu \mathrm{L}$ of medium and were allowed to attach overnight. The MTT reagent was added $(10 \mu \mathrm{L}$ per well) and the plate is incubated for 2 to $12 \mathrm{~h}$ to allow for intracellular reduction of the soluble yellow MTT to the insoluble purple formazan dye. Detergent reagent is added to each well to solubilize the formazan dye prior to measuring the absorbance of each sample in a microplate reader at $550-600 \mathrm{~nm}$. Six wells were used for each group. The sham control (irradiated) group was assigned a value $100 \%$. Inhibition of cell proliferation (\%) of the treated cells (AgNPs + IRR) was determined relative to that of irradiated cells set as $100 \%$. The results are presented as the mean \pm standard error (SE) of three independent experiments.

\subsubsection{LDH Assay}

Lactate dehydrogenase (LDH) was assayed in the current investigation to evaluate the capability of AgNPs to enhance the IR induced membrane damage of MCF-7 cells with the leakage of LDH out of the cell. The radiosensitivity of MCF-7 was examined by quantitative measurement of the activity of LDH in the supernatant and compared with the IR treatment.

In brief, $50 \mu \mathrm{l}$ of the culture supernatants from each well were transferred to the corresponding well in another microtitre plate. The LDH activity of the supernatant was measured by an LDH cytotoxicity detection kit, according to the manufacturer's instructions (Takara Biochemicals, Otsu, Japan). The LDH activity was monitored by the reduction of a tetrazolium salt (yellow) to formazan (red). One hundred microlitres of diaphorase/ $\beta$-nicotinamide adenine dinucleotide (NAD+, oxidized form) dissolved in 2-(4-indophenyl)-3-(4-nitrophenyl)-5phenyltetrazolium chloride/Na-lactate was added to each well, and the plate was incubated for $30 \mathrm{~min}$ at room temperature. After incubation, the absorbance was measured at wavelengths, $490 \mathrm{~nm}$ with microplate reader (Model 550, BioRad Laboratories, Hercules, CA, USA).

\subsubsection{DNA Fragmentation Assay}

To investigate the potential of AgNPs to enhance the radiosensitivity of MCF-7 to the IR dose induce internucleosomal DNA fragmentation, the standard method for DNA laddering assay [11] was performed. In brief, cells 
from each treated group were collected and then mixed with extraction buffer $(10 \mathrm{mM} / \mathrm{TTris}-\mathrm{HCl}$ [pH 8.0$], 0.1$ $\mathrm{M} / \mathrm{LDTA}$ [pH 8.0]) and 0.5\% SDS, was first incubated for 1 hour at room temperature and then digested in the same buffer with $200 \mu \mathrm{g} / \mathrm{ml}$ proteinase $\mathrm{K}$ (Sigma) at $50^{\circ} \mathrm{C}$. An equal volume of phenol equilibrated with 1 $\mathrm{mol} /$ Tris buffer ( $\mathrm{pH} 8.0$ ) was then added, and the tubes were placed on a roller apparatus for 1 hour. After the two phases were separated by centrifugation at $5000 \mathrm{~g}$ for 30 minutes at room temperature, the viscous aqueous phases were transferred to clean tubes, and the extractions were repeated with an equal volume of phenol/chloroform. After the second extraction, the aqueous phase was transferred mannitol, $70 \mathrm{mM}$ sucrose, $5 \mathrm{mM}$ Hepes (MSH) buffer, $\mathrm{pH}$ 7.5. The extracted DNA was separated on agarose gel electrophoresis to assess fragmentation. The bands were visualized using a UV transilluminator of a gel documentation system (BIO-RAD, Gel Doc 2000).

\subsubsection{Caspase Activity Assay}

A Caspase-3 level was demonstrated in plasma using ELISA kit [Cat No. MBS261814] and according to manufacturer's instruction provided with the kits.

\subsubsection{Detection of Apoptotic Gene Expression by Real-Time Polymerase Chain Reaction (RT-PCR)} Apoptotic signalling genes include; Caspase-3, Bax and Bcl-2 were detected by RT-PCR. The housekeeping $\beta$-actin genes were used as internal control. Total RNA was extracted from each frozen sample using TRIzol ${ }^{\circledR}$ reagent (Invitrogen) according to a standard protocol. The isolated total RNA was converted into complementary DNA (cDNA) using Moloney murine leukemia virus (M-MLV) reverse transcriptase (Promega, Madison, USA).Real-time PCR was performed using an ABI 7500 Real-Time PCR System (Applied Biosystems, Foster City, CA, USA) and an SYBR ${ }^{\circledR}$ Green PCR Master Mix (Applied Biosystems) in a final volume of $10 \mu \mathrm{l}$ with the following thermal cycling conditions: $95^{\circ} \mathrm{C}$ for $10 \mathrm{~min}$, followed by 40 cycles of $95^{\circ} \mathrm{C}$ for $15 \mathrm{~s}$ and $60^{\circ} \mathrm{C}$ for $1 \mathrm{~min}$. The sequences of PCR primer pairs used for each gene are shown in Table 1. Data were analyzed with the ABI Prism sequence detection system software and quantified using the v1.7 Sequence Detection Software from PE Biosystems (Foster City, CA, USA). The relative expression of studying genes was calculated using the comparative threshold cycle method. All values were normalized to the $\beta$-actin genes as an invariant endogenous control (reference gene). The relative quantification was then calculated by the $2^{-\Delta \Delta \mathrm{Ct}}$ method.

\subsection{Statistical Analysis}

Statistical evaluation of the data was performed using one-way analysis of variance (ANOVA), one-way analysis of variances using the SPSS package program, version 14 . The results were shown as mean \pm SE and $\mathrm{P}<$ 0.05 accepted as the minimum level of significance.

\section{Results}

\subsection{Characterization of the Biosynthesized Silver Nanoparticles (AgNPs)}

Extracellular biosynthesis of silver nanoparticles by Penicillium aurantiogresium (IMI 89372) was carried out during this work. After incubation for 72 hours with sterilized deionized distilled water, the fungal biomass was separated by filtration. The fungal cell free filtrates incubated with silver ion at the beginning of the reaction. The flasks being incubated in the dark in an environmental shaker showed a gradual change and increasing in color intensity of the medium to brown during the incubation period. The result showed synthesis of silver nanoparticles of silver ions appeared in contact with the filtrate (Figure 1).

Table 1. The sequences of PCR primer pairs.

\begin{tabular}{cc}
\hline Parameter & Primer sequence \\
\hline Caspase-3 & F: CTGGACTGCGGTATTGAGAC-3’', \\
& R: CCGGGTGCGGTAGAGTAAGC-3’ \\
Bax & F 5'-ATGGACGGTCCGGGGAGCAGC-3’ \\
& R 5'-CCCCAGTTGAAGTTGCCGTCAG-3’ \\
Bcl-2 & F 5'-GGTGCCACCTGTGGTCCACCTG-3' \\
& R 5'-CTTCACTTGTGGCCCAGATAGG-3 \\
$\beta$-actin & F: (forward) TGTTTGAGACCTTCAACACC-3' \\
& R: (reverse) TAGGAGCCAGGGCAGTAATC-3'
\end{tabular}




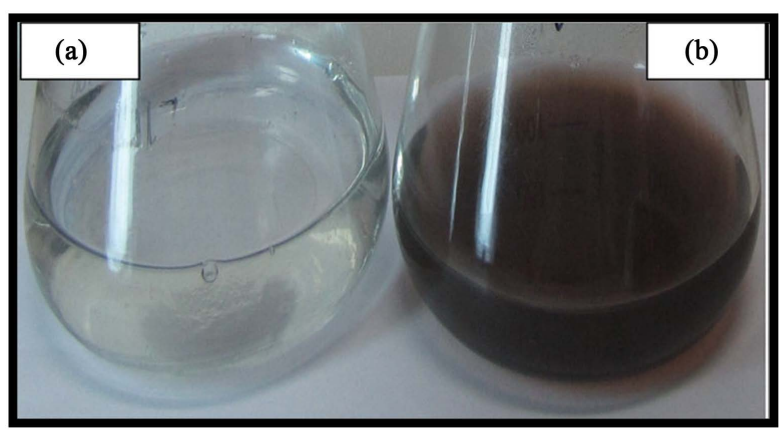

Figure 1. Culture filtrate with silver ions: (a) at the beginning of reaction and (b) after 72 h of reaction.

The change in color of the medium was noted by visual observation. The solution remained as hydrosol and no precipitation was observed. Control (without silver ion) showed no change in colour of the cell filtrate when incubated in the same environmental condition.

The present results revealed that the fungal isolate Penicillium aurantiogresium (IMI 89372) formed nanoparticles with silver nitrate in extra cellular filtrates.

In the current study, TEM micrograph of AgNPs was obtained at $25^{\circ} \mathrm{C}$ and $\mathrm{pH} 4$ as a control (directly from fungal filtered) and in $37^{\circ} \mathrm{C}$ and $\mathrm{pH} 6.0$ as an optimum conditions for the AgNPs biosynthesis process (Figure 2). The direct electron microscopic visualization allows measuring the size and shape of the silver nanoparticles formed. The micrograph showed nanoparticles with spherical in shape and measured $12.7 \mathrm{~nm}$ in size.

Silver nanoparticles from the all used fungal extracts have been characterized using XRD by various investigators. The size of silver nanoparticles can also be determined by laser diffraction. Selected area electron diffraction (SAED) spots that corresponded to the (from inside to outside of the central ring) planes of the facecentered cubic (FCC) structure of elemental silver are clearly seen in Figure 3(a). The silver particles formed can be achieved by measuring the XRD-spectrum of the samples. X-ray diffraction occurred to confirm the crystalline nature of the nano-particle and the XRD pattern obtained has been represented in Figure 3(b). The XRD pattern showed intense peaks in the whole spectrum of 20 values ranging from 20 to 80.

Currently, FTIR measurements of AgNPs were carried out after $24 \mathrm{~h}$ of incubation with the fungus to identify the possible biomolecules responsible for the reduction of the $\mathrm{Ag}^{+}$Ions and capping of the bio-reduced AgNPs synthesized by fungal filtrate. Representative spectra of obtaining nanoparticles manifests absorption peaks located at about 1045, 1245, 1299, 1361, 1377, 1488, 1550, and 1631 in the region $1000-1800 \mathrm{~cm}^{-1}$. The FTIR spectra reveal the presence of different functional groups like $\mathrm{C}-\mathrm{N}, \mathrm{C}-\mathrm{O}-\mathrm{C}$, amide linkages, 1400 to $1700 \mathrm{~cm}^{-1}$

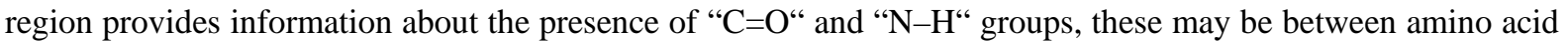
residues in polypeptides and protein in synthesized silver nanoparticles and give rise to well-known signatures in the infrared region of the electromagnetic spectrum (Figure 4(a)).

Energy dispersive X-ray spectrum (EDX) analysis shows the peak in the silver region confirming presence of elemental silver. The optical absorption peak is observed approximately at $3 \mathrm{KeV}$, which is typical for the absorption of metallic silver nanocrystalline due to surface plasmon resonance, from this we confirmed the presence of nanocrystalline elemental silver (Figure 4(b)).

\subsection{Mycosynthesized AgNPs Induced Dose Dependant Cytotoxicity}

In the present investigation the cytotoxicity of the biologically synthesized sliver NPs using Penicillium aurantiogresium (IMI 89372) was evaluated under in vitro conditions in MCF-7, HCT and Vero cell lines. This was assessed in term of cell viability by crystal violet assay for 24 hour in human cancer cells MCF-7 and HCT as well as in the normal Vero cell lines using concentrations ranging from $0.44 \mu \mathrm{g} / \mathrm{ml}$ to14 $\mu \mathrm{g} / \mathrm{ml}$. Depending on AgNPs concentration, a significant differential cytotoxic effect was testified towards the examined cells. The results showed that the synthesized AgNPs was found to be potentially cytotoxic against MCF-7 and MCT cell lines. However, MCF-7 viability were significantly inhibited by AgNPs agent with IC50 value $10.5 \mu \mathrm{g} / \mathrm{ml}$ of the concentration and MCT cells with IC50 $12.3 \mu \mathrm{g} / \mathrm{ml}$ of the concentration. The results also demonstrated that the sensitivity of the two cancer cell lines examined in the current work was higher than that of Vero cell lines (IC50 $77.4 \mu \mathrm{g} / \mathrm{ml}$ ) (Figure 5). 


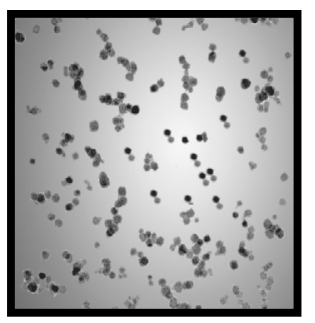

Figure 2. TEM micrograph of synthesized silver nanoparticles (scale bar: $50 \mathrm{~nm}$ ) from tested fungal extracts measured 12.7 nm.

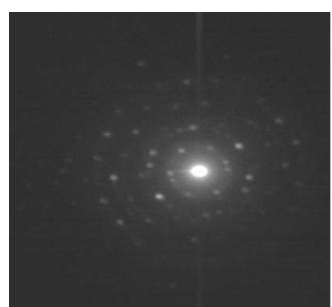

(a)

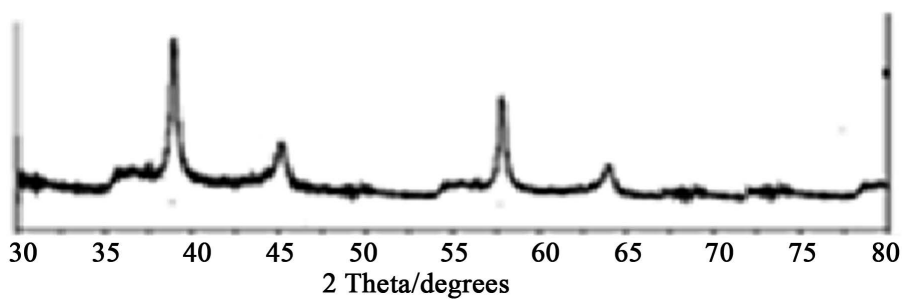

(b)

Figure 3. (a) \& (b) Selected area electron diffraction (XRD) showing the characteristic crystal planes of elemental silver from all fungal extracts used in the present study.

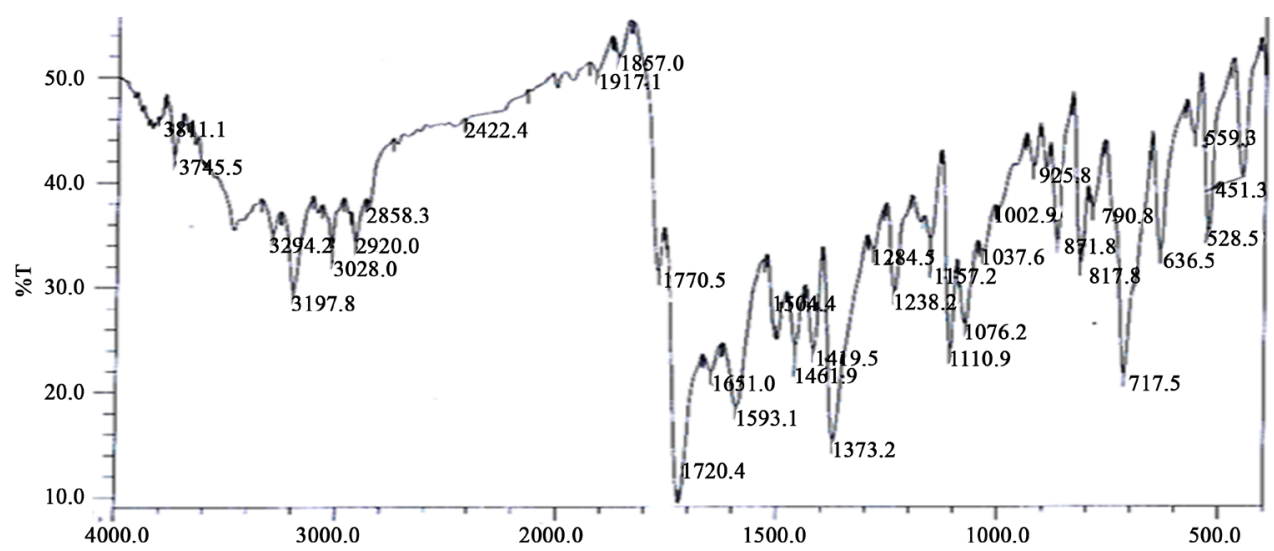

(a)

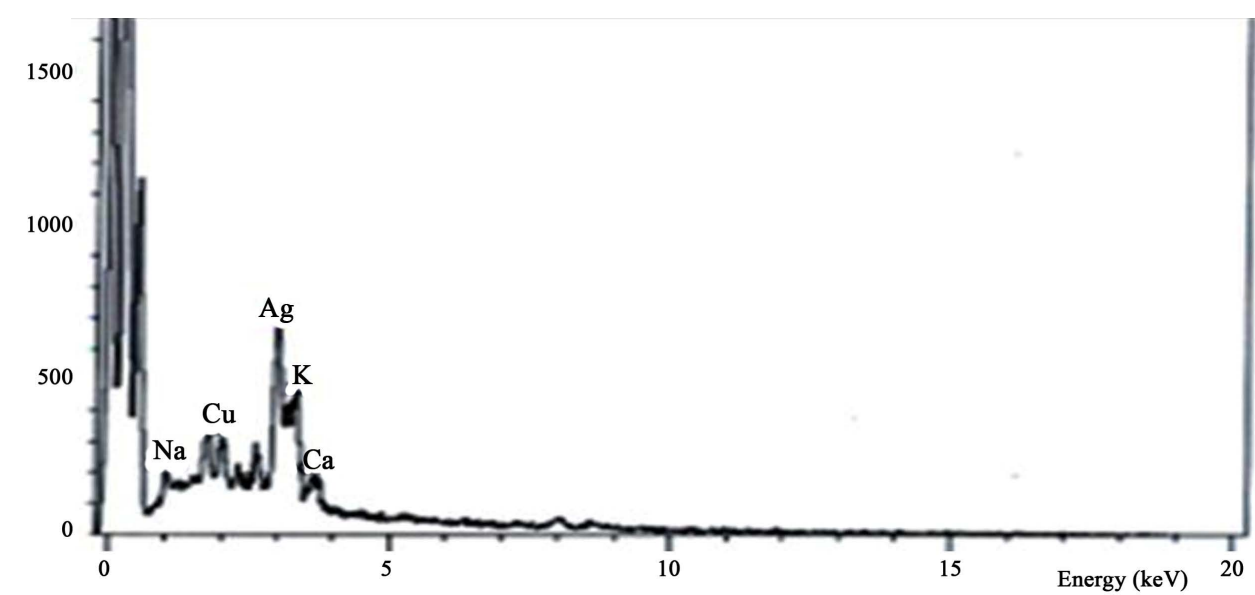

(b)

Figure 4. (a) FT-IR spectrum and (b) Energy-dispersive X-ray spectrum (EDX). 


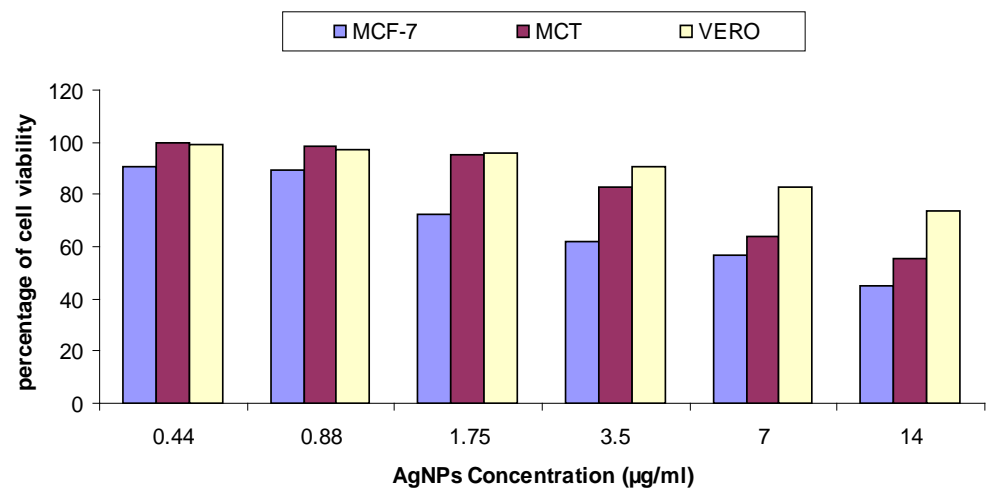

Figure 5. Cytotoxic activity of AgNPs on MCF-7, HCT and Vero cell lines as assayed by crystal violet method. The values are the mean of three separate trials \pm SE.

\subsection{Cellular Morphology Analysis}

The morphological changes of MCF-7, HCT and Vero cell lines were analyzed using inverted microscope after incubation with the highest concentration of AgNPs $(14 \mu \mathrm{g} / \mathrm{l})$ used in the current investigation for $24 \mathrm{hr}$. Both MCF-7 and HCT cancer cells showed profound morphological changes characteristic of cytotoxicity. The cells appeared aggregated, irregular in shape, detached from the substratum and floating in their culture media. Moreover, the cells showed typical apoptotic features characterized by chromatin condensation close to the nuclear envelope, associated with cytoplasmic vacuolization. These morphological changes are less pronounced in Vero cells (Figure 6).

\subsection{Silver Nanoparticles (AgNPs) Mediated Radiosensitivity of MCF-7 Cancer Cells}

To determine whether AgNPs enhanced the therapeutic effect of radiotherapy and resulted in better cytotoxic effect than radiotherapy alone, the cytotoxic effect of combined treatment with $\gamma$-irradiation and AgNPs was evaluated in comparison with the cytotoxic effect of irradiation treatment alone. The cells were treated with AgNPs of $10.55 \mu \mathrm{g} / \mathrm{ml}$ concentration for $24 \mathrm{hr}$ then irradiated with $6 \mathrm{~Gy}$. The radiosensitizing effect of AgNPs in MCF-7 cells was demonstrated 24 hours post irradiation exposure through a demonstration of its antiproliferating effect (MTT assay), cell membrane integrity (via LDH release) and DNA damage as well as apoptotic gene expression (caspase-3, Bax and Bcl-2) as well as caspase activity.

\subsection{MTT Assay}

The MTT assay implies that incubation of MCF-7 cell lines with AgNPs $(10 \mu \mathrm{g} / \mathrm{ml})$ caused significant $(\mathrm{P}<0.01)$ inhibition of cell proliferation $(65.5 \pm 2.6)$ and to $(65.2 \pm 5.7)$ when irradiation treatment applied alone $(\mathrm{P}<$ 0.01), Mean while, combination of AgNPs with IR increased the inhibition of cell proliferation $(\mathrm{P}<0.001)$ compared to control set. It is worth of mentioning that the combined treatment caused a pronounced increase in inhibition of cell proliferation compared to irradiation treatment alone $(\mathrm{P}<0.05)$ (Figure 7).

\subsection{LDH Assay}

The LDH assay is a cytotoxicity assay that measures the membrane damage by quantifying the amount of LDH released from the cytoplasm. In the current study the results revealed that AgNPs in its own and IR treatment alone caused significant $(\mathrm{P}<0.01)$ membrane damage with the leakage of LDH enzyme which correlated as indicated by the increase of the absorbance reading in LDH assay. The cyto-damage was further increased with a substantial increase in LDH release was observed in AgNPs combined with IR treatment compared to IR treatment alone $(\mathrm{P}<0.05)$ (Figure 8).

\subsection{DNA Fragmentation in MCF-7 Cell Lines}

To demonstrate the apoptotic effect of AgNPs and its enhancing capacity of IR therapy, DNA laddering assay was performed on agarose gel in MCF-7 treated cells. The results imply the presence of clear fragments in 
AgNPs and IR treated cells. These fragments increased when the cells exposed to the AgNPs combined with IR therapy confirming that AgNPs induce cell death and enhance apoptotic cell death by IR (Figure 9).

\subsection{Caspase-3 Activity in MCF-7 Cell Lines}

To investigate whether AgNPs induced apoptosis is mediated via caspae-3 pathway and enhancement of the apoptotic effect of radiotherapy via enhancing the activity of caspase-3. The data presented in Figure 10 showed significant $(\mathrm{P}<0.01)$ increase in caspase-3 activity after each of the sole treatment of AgNPs or IR. Further

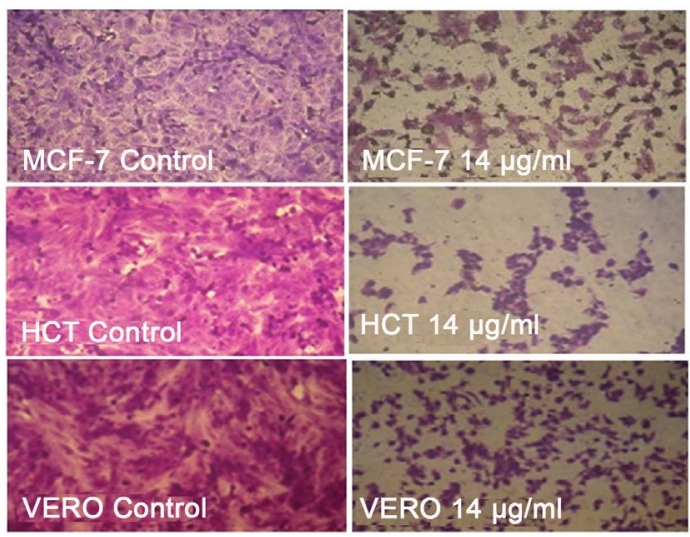

Figure 6. In vitro cytotoxicity of AgNPs. Microscopic photographs of the tested cell lines: cells were treated with or without AgNPs $(14 \mu \mathrm{g} / \mathrm{ml})$ for 24 hours using an inverted microscope at $\times 40$ magnification.

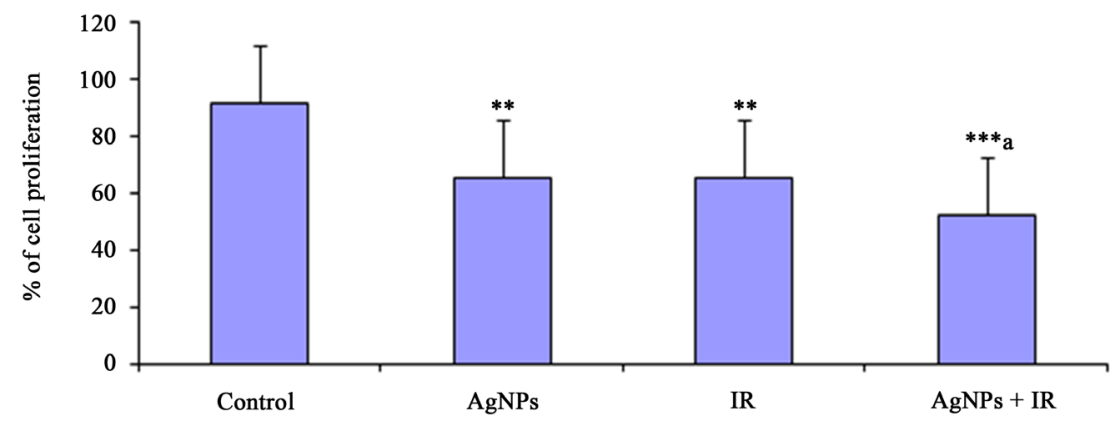

Figure 7. Radiosensitizing effect of AgNPs on cell proliferation in MCF-7 cells. The results represent the means of three separate experiments \pm the mean of standard error. Treated groups showed statistically significant differences from the control group at ${ }^{* * *} \mathrm{P}<0.001,{ }^{* *} \mathrm{P}<0.01$. AgNPs + IR showed statistically significant differences from the IR group at ${ }^{\mathrm{a}} \mathrm{P}<0.05$.

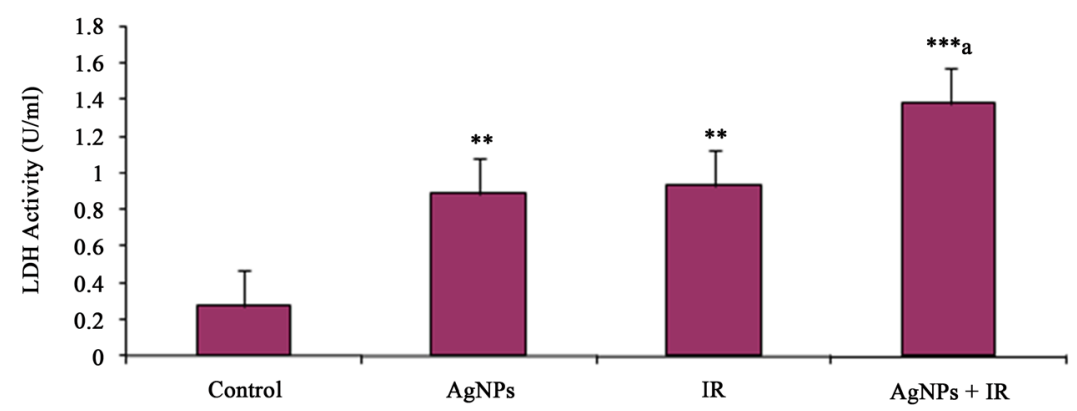

Figure 8. Radiosensitizing effect of AgNPs in MCF-7 cells as indicated by LDH activity. The results represent the means of three separate experiments \pm the mean of standard error. Treated groups showed statistically significant differences from the control group at ${ }^{* * *} \mathrm{P}<0.001,{ }^{* *} \mathrm{P}<0.01$. AgNPs + IR showed statistically significant difference from the IR group at ${ }^{\mathrm{a}} \mathrm{P}<0.05$. 


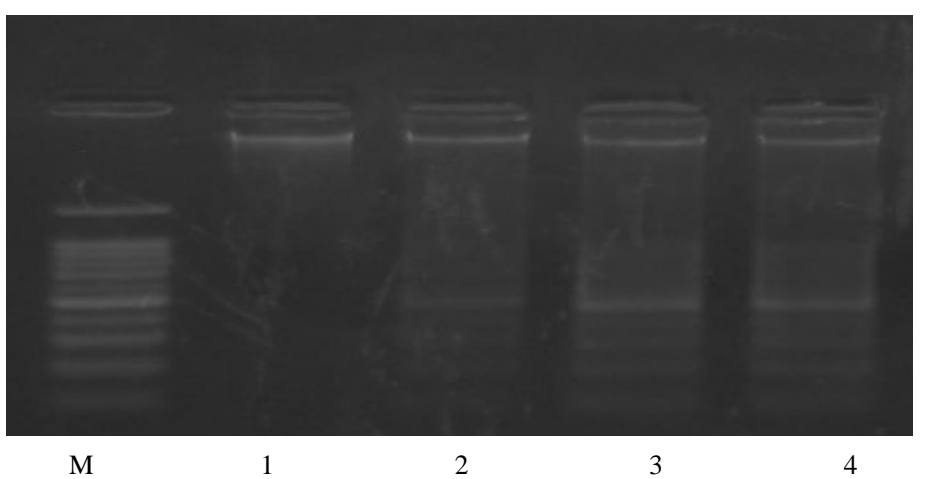

Figure 9. An agarose gel electrophoresis show the DNA fragmentation pattern which was monitored in different studied groups. Apoptotic strand breaks/streaking DNA was observed in the treated groups (2, 3 \& 4) and minimal apoptotic breaks in group 1 (cancer untreated cells).

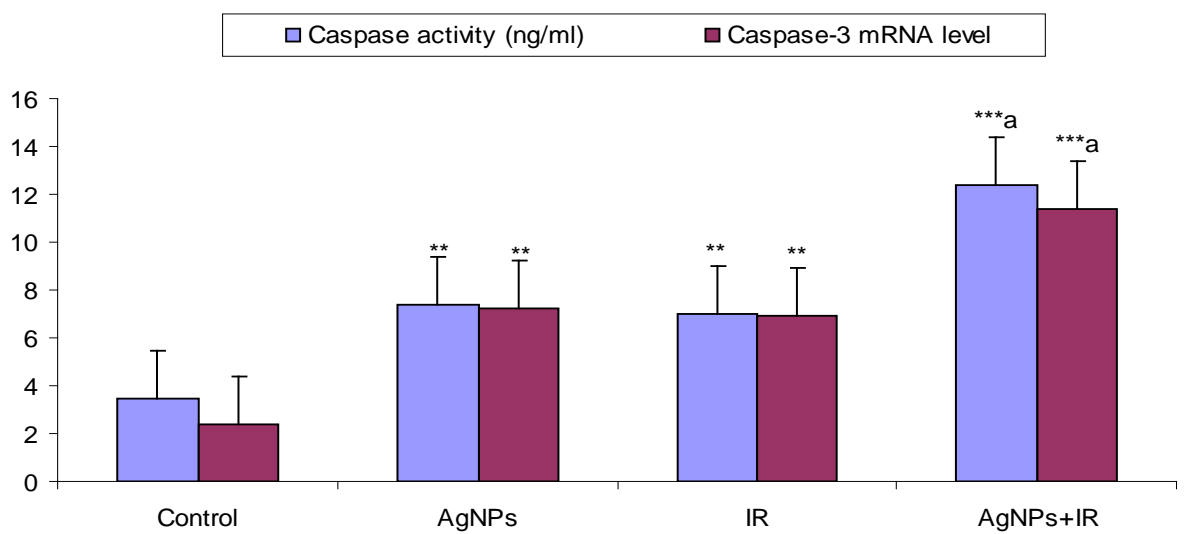

Figure 10. Radiosensitizing effect of AgNPs on caspase-3 activity in MCF-7 cells. The results represent the means of three separate experiments \pm the mean of standard error. Treated groups showed statistically significant differences from the control group at ${ }^{* * *} \mathrm{P}<0.001,{ }^{* * *} \mathrm{P}<0.01$. AgNPs + IRR showed statistically significant differences from the IR group at ${ }^{\text {a }} \mathrm{P}<0.01$.

pronounced increase in caspase-3 activity was observed after the combination of combination of both treatments compared with IR treatment alone $(\mathrm{P}<0.01)$ (Figure 10).

\subsection{Expression of Apoptotic Genes in MCF-7Cell Lines}

Evaluation of the radio sensitizing effect of AgNPs on expression of apoptotic genes caspase-3, Bax and Bcl-2 at a transcriptional level using RT PCR was performed after treatment of MCF-7 with either AgNPs at a concentration of $10.5 \mu \mathrm{M}$ for $24 \mathrm{~h}$ or irradiation at a dose of 6 Gy IR and their combination. The altered expression of the apoptotic genes is shown in Figure 11. The results showed that the mRNA expression of caspase- 3 and Bax were significantly $(\mathrm{P}<0.01)$ up regulated and the expression of anti apoptotic gene Bcl-2 was significantly $(\mathrm{P}<0.001)$ down regulated in AgNPs as well as IR treated MCF-7 cell lines. More prominent alteration was noted in caspase-3, bax $(\mathrm{P}<0.01)$ and Bcl-2 $(\mathrm{P}<0.05)$ after treatment of AgNPs combined with IR treatment in relation to IR treatment alone (Figure 11).

\subsection{Radiosensitizing Effect of AgNPs and Cellular Morphology Analysis}

Furthermore, the radio sensitizing effect of AgNPs on cellular morphology was also demonstrated upon treatment with IC50 of silver NPs (10.5 $\mu \mathrm{g} / \mathrm{ml})$ alone, IR treatment (6 Gy) alone and the combination of both. The photographs (Figure 12) showed that control (without treatment with AgNPs or radiation), the tumor cell was composed of sheets or cords of irregularly sized and shaped cells with no tendency to keratinization. Mitotic figures were commonly encountered and the tumor cells were clearly surrounded by the stroma (Figure 12(a)). 


\begin{tabular}{llll}
\hline Control & $\square$ AgNPs
\end{tabular} IR $\quad \square$ AgNPs+IR

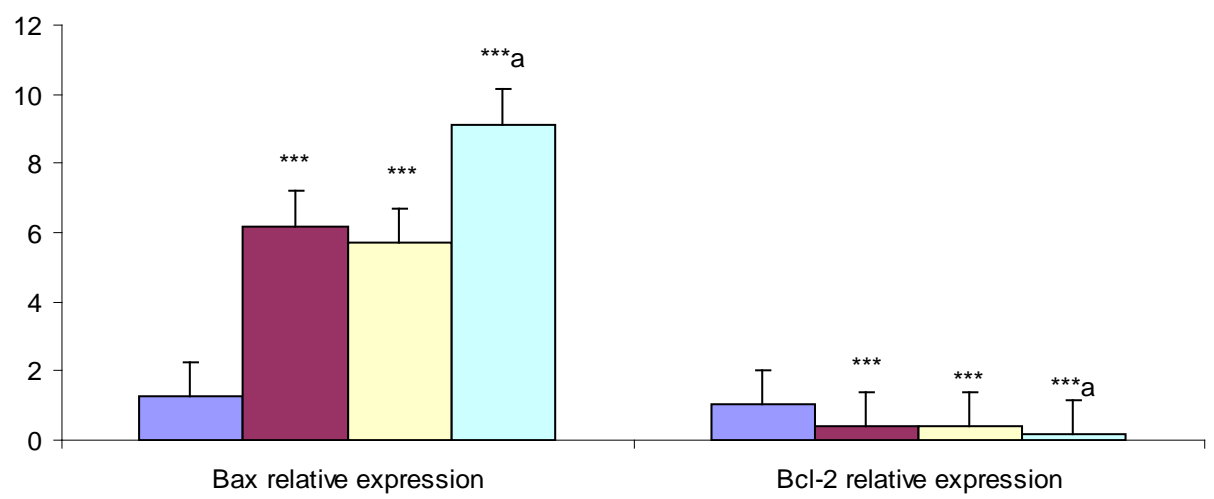

Figure 11. Radiosensitizing effect of AgNPs on the expression of the apoptotic gene Bax and anti apoptotic gene Bcl-2 in MCF-7 cell lines. The results represent the means of three separate experiments \pm the mean of standard error. Treated groups showed statistically significant differences from the control group at ${ }^{* * *} \mathrm{P}<0$.001. AgNPs + IR showed statistically significant differences from the IR group at ${ }^{\mathrm{a}} \mathrm{P}<0.01$.

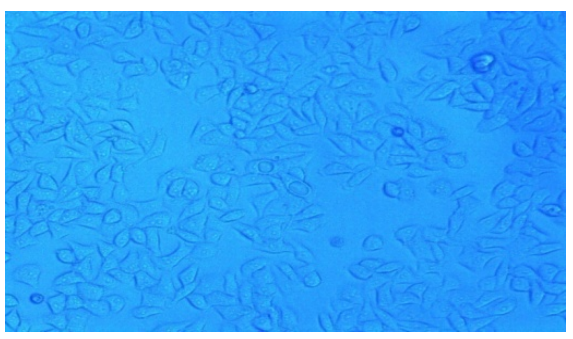

(a)

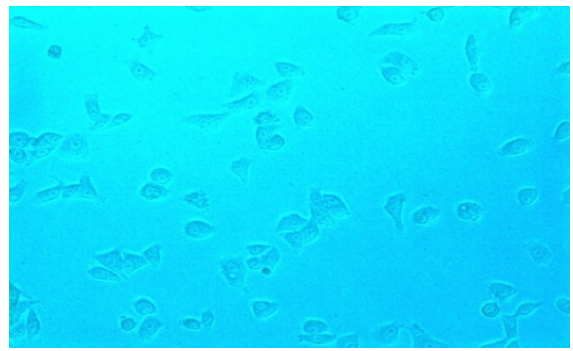

(c)

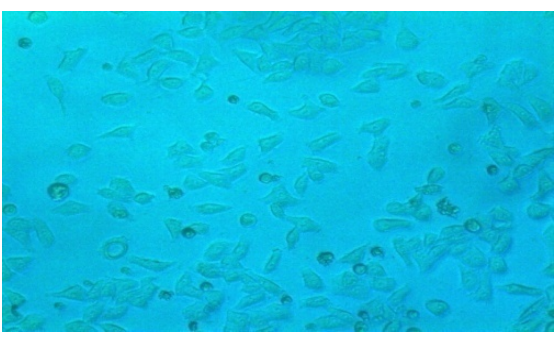

(b)

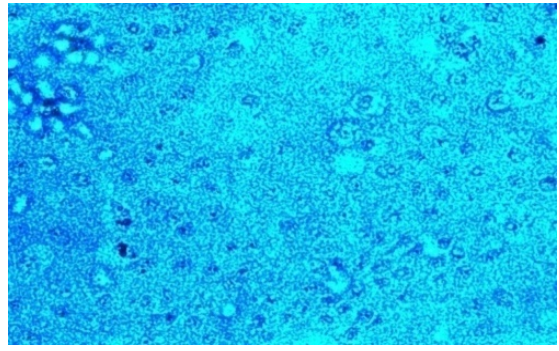

(d)

Figure 12. Radio sensitizing effect of AgNPs on cellular morphology. Microscopic photographs of (a): untreated MCF-7 cell lines and (b): cells treated with AgNPs $(10.5 \mu \mathrm{g} / \mathrm{ml})$ for 24 hour alone; (c) cells treated with 6 Gy irradiation alone and (d) cells treated with the combination of both, using inverted microscope at $\times 40$ magnifications.

The cells were gradually keratinized after treatment with AgNPs occasionally showing malignant squamous pearls (Figure 12(b)). The individual cell keratinization and cancer pearls were more prominent after treatment with either AgNPs or radiation (Figure 12(b) and Figure 12(c)).

After treatment with both, almost all the tumor cells were degenerated to necrosis, with only a pearl-like structure and very few cellular elements remaining remarkable nuclear hypochromasia were enmeshed within the fibrous stroma (Figure 12(d)).

\section{Discussion}

The conventional methods, particularly chemical and physical procedures have been widely used to synthesize 
metal nanoparticles (NPs). However, the procedures of these methods are usually cost and potentially hazardous to the environment. Nowadays, there is a growing need to develop clean, nontoxic and eco-friendly methods.

The growing success and ease of formation of nanoparticles using micro-organisms have been paid much attention, because of their advantages over the chemical and physical methods. Therefore, it was of great significance to explore a novel fungi strain for synthesizing AgNPs based on the biodiversity.

To the best of our knowledge, this the first report on the biological synthesis of AgNPs using a strain of Penicillium aurantiogresium (IMI 89372). In this study the fungal biomass was exposed to an aqueous $1 \mathrm{Mm} \mathrm{Ag-}$ NO3 solution resulted in the reduction of the metal ions and formation of silver nanoparticles. The synthesized AgNPs were spherical in shape and $12.7 \mathrm{~nm}$ in size as characterized using UV-visible spectroscopy, TEM, XRD, EDX and FTIR analysis.

It has been demonstrated that different species of fungi are extremely good candidates in the synthesis of silver nanoparticles (AgNPs) [12], this is because of the secretion much higher amounts of bioactive substances, which made fungi to be more suitable to produce large-scale nanoparticle. In addition, the process of extracellular nanoparticle biosynthesis using fungi is much easier than bacteria production [13]. The present results are in consistent with studies reported the nanoparticle biosynthesis using fungi (Fusarium oxysporum) [14]. The mechanism of silver nanoparticle production by fungi is the trapping of $\mathrm{Ag}+$ ions at the surface of the fungal wall and the subsequent reduction of the $\mathrm{Ag}^{+}$by the nitrate enzyme present in the fungal cell wall membrane into AgNPs [15].

In the present investigation the cytotoxicity and radio sensitizing capacity of the AgNPs were demonstrated under in vitro conditions.

The cell viability assay which is one of the important methods for toxicology analysis which explain the cellular response to toxic materials, it can provide information on cell death, survival, and metabolic activities [7].

In the current work, crystal violet assay was used to assess the effect of AgNPs at different concentrations ranging $0.44 \mu \mathrm{g} / \mathrm{ml} \mathrm{-} 14 \mu \mathrm{g} / \mathrm{ml}$ for $24 \mathrm{hr}$ on the viability of MCF-7 and MCT cancer cells and normal Vero cell lines.

In agreement with others, our results revealed that AgNPs exhibit significant cellular cytotoxicity which significantly reduced the cell viability of the treated cells as a function of AgNPs concentration [16]-[18].

Of note, finding of the present study revealed that AgNPs showed cell specific cytotoxicity, where MCF-7 appeared to be more sensitive to AgNPs toxicity (IC50 values $10.5 \mu \mathrm{g} / \mathrm{ml}$ ) over MCT cell lines (IC50 values $12.3 \mu \mathrm{g} / \mathrm{ml}$ ), meanwhile, the Vero cell lines exhibited the less cytotoxicity with IC50 $77.4 \mu \mathrm{g} / \mathrm{ml}$.

In line with our results, many investigators showed that AgNPs induce in vitro cytotoxic responses often specific to cell types [8] [19] [20] resulting in varying degrees of toxicity and was depending on nanoparticle size, concentration, and exposure time [21] [22].

In correlation with the cytotoxicity results and in agreement with other reports [23], analysis of microscopic cell morphology in Figure 6 revealed the morphological changes of the cell lines treated with AgNPs $(14 \mu \mathrm{g} / \mathrm{ml})$ for $24 \mathrm{hr}$. As visualized under the inverted light microscope, the cells appeared to be shrinking, detached from substratum, and nuclear condensation and fragmentation were evident.

The in vitro cytotoxic potential of AgNPs could attribute to the generation of ROS which have been shown to play an important role in induction of apoptosis [24]. Other investigators endorsed the cytotoxicity of AgNPs to the oxidative stress caused by their release of $\mathrm{Ag}^{+}$in cells as both silver nanoparticles and silver ions which could trigger the production of hydroxyl radicals in acidic endo/lysosomes [25] and induce membrane fluidity [7]-[25].

Radiosensitization makes cancer cells to be more susceptible to radiation damage, allowing a low dose of radiation to be used during radiotherapy [26]. It has been demonstrated to improve treatment outcome and reduce the side effects [27]. The interaction between AgNPs and ionizing radiation may enhance the therapeutic effects, thus allowing a reduction in ionizing radiation dose and thereby lowering the potential side effects [28]. For this reason, in the current study, the radio sensitizing effect of AgNPs in combination with radiation therapy induced inhibition of MCF-7 proliferation and induced apoptosis was evaluated.

Cell proliferation has been suggested as an important factor in the prognosis of malignant tumors [29]. In the present study, the MTT assay was used to investigate the enhancing antiproliferative effect of AgNPs at a concentration of $10.5 \mu \mathrm{g} / \mathrm{ml}$ combined with radiotherapy (6 Gy). Our quantitative analysis revealed that the percentages of cell proliferation were significantly lower in the AgNPs and radiation combination groups than that in the irradiation treatment alone indicating that AgNPs enhanced the antiproliferating effect of radiotherapy in 
MCF-7 cell lines. In agreement with our results, several investigators evidenced that AgNPs have been reported to possess radiation dose-enhancing effects [30] [31].

Lactate dehydrogenase (LDH) is a soluble cytosolic enzyme, which is released into the extracellular medium due to membrane damage consequently lead to apoptosis. Thus the content of AgNPs induced cytotoxicity was determined quantitatively by measuring measuring the activity of LDH in the supernatant as an indirect method [19]. LDH leakage into culture supernatant was measured in MCF-7 cells treated with AgNPs and/or irradiation to determine cell membrane damage. Moreover, we examined whether AgNPs enhanced irradiation induced MCF cell death through augmenting of irradiation-induced the membrane leakage. In this study, the LDH activity in the medium was significantly higher in cells treated with the sole AgNPs or IR treatment alone compared to the untreated control cells. In close relationship with our results, other investigators reported that AgNPs significantly affect the cell membrane integrity and caused LDH leakage in a concentration dependent manner and after 24 hour of AgNPs exposure in liver rat cells and in L929 fibroblasts [32] [33]. Furthermore it has been evidenced that IR-induced apoptotic cell death was most likely associated release of LDH [34].

It is worth mentioning that, in combined treatment AgNPs enhanced the cytotoxicity of MCF-7 cells to the radiation dose and caused more killing of cells than that observed in the sole AgNPs and irradiation treatments. In line with our results, other studies emphasized that PEG-GNPs could enhance the therapeutic sensitivity in breast cancer EMT-6 cells [34]. Also, Zhang et al. [35] evidenced the radiosensitizing effect GSH- and BSAGNPs in HeLa cells. They attributed this effect to the enhanced DNA damaging effect induced by the photoelectric effect and Compton scattering of the heavy metal.

Apoptosis is a well-recognized cell death mechanism in cancer treatment, through which cytotoxic agents kill tumor cells [31]. DNA considered as one of the important characteristics of cell death. Radiotherapy and chemotherapy are important integral parts of breast cancer treatment which result in DNA damage and can lead to apoptotic death [36]. In the present investigation, the MCF-7 cell lines were treated with the sole treatments of AgNPs (10.5 $\mu \mathrm{g} / \mathrm{ml})$, irradiation (6 Gy) and their combination (AgNPs + IRR) for $24 \mathrm{hr}$. DNA was then extracted from cell lysate followed by detection by agaros gel.

The laddering pattern showed DNA fragments in MCF-7 cells treated with AgNPs alone or irradiation by itself. Adding strengthen to the fact, more pronounced fragmented DNA ladders was observed after applying the AgNPs combined with irradiation (IR) therapy, suggesting that AgNPs enhanced IR induced apoptotic cell death. In close relationship with our findings, other studies have been reported that when cancerous cell lines treated with AgNPs exhibited formation of DNA ladder [37] and resulted in DNA damage [38] caused induction of oxidative stress [39].

These results were further confirmed by the morphological analysis of the treated cells (Figure 12) which revealed that the cells were shrunken, irregular in size, detached from the substratum and became floated in the culture media which appeared greater after exposure to the combined therapy. All these observation of the cell morphology emphasized induction of apoptosis and appeared in a good correlation with our results evidenced by MTT assay, LDH leakage assay and DNA laddering pattern. The results could be explained as a result of the production of ROS and the subsequent induction of oxidative stress which play an important role in cell injury which lead to DNA damage and consequently apoptotic cell death [7] [18] [40].

In the same line with these results, many investigators demonstrated that AgNPs resulted in DNA oxidative damage suggesting AgNPs mediate ROS-induced genotoxicity and play important role in AgNPs-induced toxicity [41]. Moreover, Zhang and colleagues reported that $\gamma$-radiation can be absorbed directly by DNA, leading to ionization of both the nucleobases and sugars, directly generating DNA damage [35].

Caspase- 3 is known to be the major effector of the apoptotic machinery and plays an important role in the apoptotic pathway [20]. To investigate whether apoptosis is mediated by caspase-3, was demonstrated its mRNA level and caspase-3 activity at the biochemical level after treatment with the sole AgNPs $(10.5 \mu \mathrm{g} / \mathrm{ml})$, irradiation alone (6 Gy) or in combination.

In agreement with the present finding, a work done by Satyavani and colleagues revealed that AgNPs induced cell death via activation of caspase-3 activity and DNA fragmentation which are both apoptotic events [42]. The increased level of caspase-3 activity was observed in human breast cancer cells MDA-MB-231 in response to the cytotoxic potential of the biologically synthesized AgNPs treatment [21]. The activation of caspase-3 was also demonstrated following irradiation [43]. Of note, the results displayed that combined treatment of AgNPs and irradiation enhanced activation of caspase-3 activity compared to either of sole treatment. These results are in a good correlation with up regulation of caspase-3 gene expression after incubation with AgNPs alone, irradi- 
ation alone. Compared with the groups treated with AgNPs alone, irradiation alone, we noticed that combined treatment of AgNPs plus irradiation triggered the expression of caspase-3 genes.

These finding suggest that $\gamma$-irradiation in combination with AgNPs up regulate caspase-3 gene expression and modulates caspase-3 activity and triggered apoptosis following the loss of membrane integrity and DNA damage, thereby enhancing apoptotic cell death in a caspase-3 dependant pathway.

The expression of genes that regulate apoptosis such as Bax promoting apoptosis and Bcl-2 promoting survival [44] are responsible for the induction of the mitochondrial pathway, leading to the activation of caspase proteins [45].

Regulation of caspases as well as Bax, and Bcl-2 gene expression considered to be of the important regulatory mechanisms of cell apoptosis [46]. In the current study, an inverse relationship between the Bax and Bcl-2 gene expression was noticed under the effect of each of the sole treatments of AgNPs (10.5 $\mu$ g) and irradiation (6 Gy) and the combined treatment with AgNPs plus irradiation. However, the Pro-apoptotic Bax gene expression was significantly increased and showed that Bax and Bcl-2 gene expression are regulated differently with AgNPs alone and irradiation alone. More pronounced alteration of these genes expression was noticed after the combined treatment. The results suggest the radiosensitizing effect of AgNPs enhanced radiation induced up regulation of Bax and down regulation of Bcl-2 cell, thereby increasing the cell killing effect beyond either of the sole treatments alone. The results also, pointed to that the expression of these genes might be responsible for the control of the apoptotic cell death.

Our observations are in consistent with studies demonstrated that AgNPs have been reported to possess radiation dose-enhancement effects on different human cancer cell, including MGC-803 [31], U-231 breast cancer cells [47] and A549 lung cancer cells [48]. Liu and co-workers found that AgNPs treatment followed by radiotherapy resulted in antiproliferative and proapoptotic effect [30]. Colasanti and Co workers explained the enhancing effect of AgNPs to the radiation dose. They evidenced that combination of cytotoxic agent could enhance the dose of ionizing radiation to generate an additive effect that could be more useful in reduction of the therapeutic dose of radiation to obtain the same therapeutic effect [51].

The mechanism of radiosensitization by AgNPs could be due to disrupting normal cellular function and also due to affecting the membrane integrity, induced various apoptotic signaling genes of mammalian cells leading to programmed cell death [49]. Su and co-workers reported that the radiosensitizing potential of AgNPs may be related to the release of $\mathrm{Ag}^{+}$cation from the $\mathrm{Ag}$ nanostructures inside cells. $\mathrm{Ag}^{+}$cation has the ability to capture electron and thus functions as an oxidative agent, which could further reduce the ATP content of the cell and increase production of ROS [50].

Moreover, it has been emphasized that the cytotoxicity of $\gamma$ irradiation therapy is due to the generation of ROS and is a direct consequence of DNA double strand breaks and ultimately provoking the cell death [51]. As radiation and AgNPs inhibit cell proliferation and consequently induce cell death by the same mechanisms, thus the radiosenthetizing effect of AgNPs could attribute to a synergistic effect.

\section{Conclusion}

In the present study, we have successfully synthesized and prepared stable, spherical AgNPs of $12.7 \mathrm{~nm}$ in size using the fungus Penicillium aurantiogresium (IMI 89372) which is green, environmentally friendly, cost effective, and rapid method for synthesis of AgNPs. The prepared AgNPs showed cell type specific cytotoxicity and could reduce cell viability in a dose dependent manner with significant morphological changes in MCF-7 and HCT cancer cells. AgNPs were more cytotoxic towards MCF-7 than MCT cell lines. These observations are less prominent in Vero cell lines. Based on our results, the combination of AgNPs and irradiation treatment could enhance gamma irradiation induced killing of MCF-7 cancer cells by inhibiting proliferation of the cells, increasing of LDH and caspase-3 activity and alteration of caspase-3, Bax and Bcl-2 genes expression. The radiosensitizing effect could be endorsed to the synergistic effect of free radicals induced by the combination of irradiation and AgNPs that increased the oxidative stress and induced apoptotic cell death. Further systemic and comparative studies are required to achieve the best in vivo radiosensitizing effect with a focus on the exact underlying molecular mechanisms.

\section{References}

[1] Yu, M.K., Park, J. and Jon, S. (2012) Targeting Strategies for Multifunctional Nanoparticles in Cancer Imaging and 
Therapy. Theranostics, 2, 3-44. http://dx.doi.org/10.7150/thno.3463

[2] Chen, X. and Schluesener, H.J. (2008) Nanosilver: A Nanoproduct in Medical Application. Toxicology Letters, 176, 1-12. http://dx.doi.org/10.1016/j.toxlet.2007.10.004

[3] Thakkar, K.N., Mhatre, S.S. and Parikh, R.Y. (2010) Biological Synthesis of Metallic Nanoparticles. Nanomedicine, 6, 257-262. http://dx.doi.org/10.1016/j.nano.2009.07.002

[4] Parikh, R.Y., Singh, S., Prasad, B.L., Patole, M.S., Sastry, M. and Shouche, Y.S. (2008) Extracellular Synthesis of Crystalline Silver Nanoparticles and Molecular Evidence of Silver Resistance from Morganella sp.: Towards Understanding Biochemical Synthesis Mechanism. ChemBioChem, 9, 1415-1422. http://dx.doi.org/10.1002/cbic.200700592

[5] Kilin, D.S., Prezhdo O.V. and Xia, Y. (2008) Shape-Controlled Synthesis of Silver Nanoparticles: Ab Initio Study of Preferential Surface Coordination with Citric Acid. Chemical Physics Letters, 6, 113-116. http://dx.doi.org/10.1016/j.cplett.2008.04.046

[6] Sriram, M.I., Kanth, S.B., Kalishwaralal, K. and Gurunathan, S. (2010) Antitumor Activity of Silver Nanoparticles in Dalton’s Lymphoma Ascites Tumor Model. International Journal of Nanomedicine, 5, 753-762.

[7] AshaRani, P.V., Hande, M.P. and Valiyaveettil, S. (2009) Anti-Proliferative Activity of Silver Nanoparticles. BMC Cell Biology, 10, 65. http://dx.doi.org/10.1186/1471-2121-10-65

[8] Zhang, X.F., Choi, Y.J., Han, J.W., Kim, E., Park, J.H., Gurunathan, S. and Kim, J.H. (2015) Differential Nanoreprotoxicity of Silver Nanoparticles in Male Somatic Cells and Spermatogonial Stem Cells. International Journal of Nanomedicine, 10, 1335-1357.

[9] Kathiresan, K., Manivannan, M.A. and Nabeel, B. (2009) Studies on Silver Nanoparticles Synthesized by a Marine Fungus, Penicillium fellutanum Isolated from Coastal Mangrove Sediment. Colloids and Surfaces B: Biointerfaces, 71, 133-137. http://dx.doi.org/10.1016/j.colsurfb.2009.01.016

[10] Mosmann, T. (1983) Rapid Colorimetric Assay for Cellular Growth and Survival: Application to Proliferation and Cytotoxicity Assays. Journal of Immunological Methods, 65, 55-63. http://dx.doi.org/10.1016/0022-1759(83)90303-4

[11] Siu, P.M. and Always, S.E. (2005) Mitochondria-Associated Apoptotic Signalling in Denervated Rat Skeletal Muscle. The Journal of Physiology, 565, 309-323. http://dx.doi.org/10.1113/jphysiol.2004.081083

[12] Ahmad, A, Mukherjee, P., Senapati, P., Mandal, D., Khan, M.I. and Kumar, R. (2003) Extracellular Biosynthesis of Silver Nanoparticles Using the Fungus Fusarium oxysporum. Colloids and Surfaces B: Biointerfaces, 28, 313-318. http://dx.doi.org/10.1016/S0927-7765(02)00174-1

[13] Bharde, A., Rautaray, D., Bansal, V., Sanyal, M. and Sastry, M. (2006) Extracellular Biosynthesis of Magnetite Using Fungi. Small, 2, 135-141. http://dx.doi.org/10.1002/smll.200500180

[14] Ahmad, A., Senapati, M. and Sastry, M. (2003) Extracellular Biosynthesis of Monodispersed Gold Nanoparticles by a Novel Extermophillic Actinomycete, Thermonospora sp. Langmuir, 19, 3550-3553. http://dx.doi.org/10.1021/la026772l

[15] Swathi, G., Sridevi, A., Sandya, A., Praveen, B. and Narasimha, G. (2014) Biosynthesis, Characterization and Antibacterial Activity of Silver Nanoparticles by Soil Fungi Pencillium sps. International Journal of Drug Delivery, 6, 165-171.

[16] Sukirtha, R., Priyanka, K.M., Antony, J.J., et al. (2012) Cytotoxic Effect of Green Synthesized Silver Nanoparticles Using Melia azedarach against in Vitro HeLa Cell Lines and Lymphoma Mice Model. Process Biochemistry, 47, $273-$ 279. http://dx.doi.org/10.1016/j.procbio.2011.11.003

[17] Dziedzic, A., Kubina, R., Bułdak, R.J., Skonieczna, M. and Cholewa, K. (2016) Silver Nanoparticles Exhibit the Dose-Dependent Anti-Proliferative Effect against Human Squamous Carcinoma Cells Attenuated in the Presence of Berberine. Molecules, 21, 365. http://dx.doi.org/10.3390/molecules21030365

[18] Franco-Molina, M.A., Mendoza-Gamboa, E., Sierra-Rivera, C.A., Gómez-Flores, R.A., Zapata-Benavides, P., Castillo-Tello, P., Alcocer-González, J.M., Miranda-Hernández, D.F., Tamez-Guerra, R.S. and Rodríguez-Padilla, C. (2010) Antitumor Activity of Colloidal Silver on MCF-7 Human Breast Cancer Cells. Journal of Experimental \& Clinical Cancer Research, 29, 148. http://dx.doi.org/10.1186/1756-9966-29-148

[19] Gurunathan, S., Han, J.W., Eppakayala, V., Jeyaraj, M. and Kim, J.H. (2013) Cytotoxicity of Biologically Synthesized Silver Nanoparticles in MDA-MB-231 Human Breast Cancer Cells. BioMed Research International, 2013, Article ID: 535796. http://dx.doi.org/10.1155/2013/535796

[20] Jeyaraj, M., Sathishkumar, G., Sivanandhan, G., MubarakAli, D., Rajesh, M., Arun, R., Kapildev, G., Manickavasagam, M., Thajuddin, N., Premkumar, K. and Ganapathi, A. (2013) Biogenic Silver Nanoparticles for Cancer Treatment: An Experimental Report. Colloids and Surfaces B: Biointerfaces, 106, 86-92. http://dx.doi.org/10.1016/j.colsurfb.2013.01.027

[21] Park, S., Lee, Y.K., Jung, M., Kim, K.H., Chung, N., et al. (2007) Cellular Toxicity of Various Inhalable Metal Nano- 
particles on Human Alveolar Epithelial Cells. Inhalation Toxicology: International Forum for Respiratory, 19, 59-65. http://dx.doi.org/10.1080/08958370701493282

[22] Hess, L.K., Jones, L., Schlager, J.J., et al. (2008) Unique Cellular Interaction of Silver Nanoparticles: Size-Dependent Generation of Reactive Oxygen Species. Journal of Physical Chemistry B, 112, 13608-13619. http://dx.doi.org/10.1021/jp712087m

[23] Kulandaivelu, B. and Gothandam, K.M. (2016) Cytotoxic Effect on Cancerous Cell Lines by Biologically Synthesized Silver Nanoparticles. Brazilian Archives of Biology and Technology, 59, e16150529. http://dx.doi.org/10.1590/1678-4324-2016150529

[24] Liu, W., Wu, Y., Wang, C., Li, H.C., Wang, T., Liao, C.Y., Cui, L., Zhou, Q.F., Yan, B. and Jiang, G.B. (2010) Impact of Silver Nanoparticles on Human Cells Effect of Particle Size. Nanotoxicology, 4, 319-330. http://dx.doi.org/10.3109/17435390.2010.483745

[25] Foldbjerg, R., Olesen. P., Hougaard, M., Dang, D.A., Hoffmann, H.J. and Autrup, H. (2009) PVP-Coated Silver Nanoparticles and Silver Ions Induce Reactive Oxygen Species, Apoptosis and Necrosis in THP-1 Monocytes. Toxicology Letters, 190, 156-162. http://dx.doi.org/10.1016/j.toxlet.2009.07.009

[26] Lee, I.J. and Seong, J.S. (2011) Radiosensitizers in Hepatocellular Carcinoma. Seminars in Radiation Oncology, 21, 303-311. http://dx.doi.org/10.1016/j.semradonc.2011.05.008

[27] McGinn, C.G., Shewach, D.S. and Lawrence, T.S. (1996) Radiosensitizing Nucleotides. Journal of the National Cancer Institute, 88, 1193-1203. http://dx.doi.org/10.1093/jnci/88.17.1193

[28] Swanner, J., Mims, J., Carroll, D.L., Akman, S.A., Furdui, C.M., Torti, S.V. and Singh, R.N. (2015) Differential Cytotoxic and Radiosensitizing Effects of Silver Nanoparticles on Triple-Negative Breast Cancer and Non-Triple-Negative Breast Cells. International Journal of Nanomedicine, 10, 3937-3953.

[29] Maeda, K., Chung, Y.S., Takatsuka, S., Ogawa, Y., Sawada, T., Yamashita, Y., Onoda, N., Kato, Y., Nitta, A. and Arimoto, Y. (1995) Tumor Angiogenesis as a Predictor of Recurrence in Gastric Carcinoma. Journal of Clinical Oncology, 13, 477-481.

[30] Liu, P.D., Huang, Z.H., Chen, Z., Xu, R., Wu, H., Zang, F., Wang, C. and Gu, N. (2013) Silver Nanoparticles: A Novel Radiation Sensitizer for Glioma? Nanoscale, 5, 11829-11836. http://dx.doi.org/10.1039/c3nr01351k

[31] Huang, P., Yang, D.P., Zhang, C., Lin, J., He, M., Bao, L. and Cui, D. (2011) Protein-Directed One-Pot Synthesis of Ag Microspheres with Good Biocompatibility and Enhancement of Radiation Effects on Gastric Cancer Cells. Nanoscale, 3, 3623-3626. http://dx.doi.org/10.1039/c1nr10586h

[32] Hussain, S.M., Hess, K.L., Gearhart, J.M., Geiss, K.T. and Schlager, J.J. (2005) In Vitro Toxicity of Nanoparticles in BRL 3A Rat Liver Cells. Toxicology in Vitro, 19, 975-983. http://dx.doi.org/10.1016/j.tiv.2005.06.034

[33] Park, M.V., Neigh, A.M., Vermeulen, J.P., de la Fonteyne, L.J., Verharen, H.W., Briedé, J.J., van Loveren, H. and de Jong, W.H. (2011) The Effect of Particle Size on the Cytotoxicity, Inflammation, Developmental Toxicity and Genotoxicity of Silver Nanoparticles. Biomaterials, 32, 9810-9817. http://dx.doi.org/10.1016/j.biomaterials.2011.08.085

[34] Sohn, D., Essmann, F., Schulze-Osthoff, K. and Jänicke, R.U. (2006) P21 Blocks Irradiation-Induced Apoptosis Downstream of Mitochondria by Inhibition of Cyclin-Dependent Kinase-Mediated Caspase-9 Activation. Cancer Research, 66, 11254-11262. http://dx.doi.org/10.1158/0008-5472.CAN-06-1569

[35] Zhang, X.D., Chen, J., Luo, Z., Wu, D., Shen, X., Song, S.S., et al. (2014) Enhanced Tumor Accumulation of Sub-2 Nm Gold nanoclusters for Cancer Radiation Therapy. Advanced Healthcare Materials, 3, 133-141. http://dx.doi.org/10.1002/adhm.201300189

[36] Elmore, S. (2007) Apoptosis: A Review of Programmed Cell Death. Toxicology Pathology, 35, 495-516. http://dx.doi.org/10.1080/01926230701320337

[37] Kalishwaralal, K., Deepak, V., Pandian, S.R.K., et al. (2010) Biosynthesis of Silver and Gold Nanoparticles Using Brevibacterium casei. Colloids and Surfaces B: Biointerfaces, 77, 257-262. http://dx.doi.org/10.1016/j.colsurfb.2010.02.007

[38] Hsin, Y.H., Chen, C.F., Huang, S., Shih, T.S., Lai, P.S. and Chueh, P.J. (2008) The Apoptotic Effect of Nanosilver Is Mediated by a ROS- and JNK-Dependent Mechanism Involving the Mitochondrial Pathway in NIH3T3 Cells. Toxicology Letters, 179, 130-139. http://dx.doi.org/10.1016/j.toxlet.2008.04.015

[39] Lim, D.H., Jang, J., Kim, S., Kang, T., Lee, K. and Choi, I.H. (2012) The Effects of Sub-Lethal Concentrations of Silver Nanoparticles on Inflammatory and Stress Genes in Human Macrophages Using cDNA Microarray Analysis. Biomaterials, 33, 4690-4699. http://dx.doi.org/10.1016/j.biomaterials.2012.03.006

[40] Kim, S. and Ryu, D.Y. (2013) Silver Nanoparticle-Induced Oxidative Stress, Genotoxicity and Apoptosis in Cultured Cells and Animal Tissues. Journal of Applied Toxicology, 33, 78-89. http://dx.doi.org/10.1002/jat.2792

[41] Kim, J.S., Sung, J.H., Ji, J.H., Song, K.S., Lee, J.H., Kang, C.S., et al. (2011) In Vivo Genotoxicity of Silver Nanopar- 
ticles after 90-Day Silver Nanoparticle Inhalation Exposure. Safety and Health at Work, 2, 34-38. http://dx.doi.org/10.5491/SHAW.2011.2.1.34

[42] Satyavani, K., Gurudeeban, S., Ramanathan, T. and Balasubramanian, T. (2011) Biomedical Potential of Silver Nanoparticles Synthesized from Calli Cells of Citrullus colocynthis (L.) Schrad. Journal of Nanobiotechnology, 9, 43. http://dx.doi.org/10.1186/1477-3155-9-43

[43] Zhang, Y., Guo, J., Qi, Y., Shao, Q. and Liang, J. (2014) The Prevention of Radiation-Induced DNA Damage and Apoptosis in Human Intestinal Epithelial Cells by Salvianic Acid A. Journal of Radiation Research and Applied Sciences, 7, 274-285. http://dx.doi.org/10.1016/j.jrras.2014.05.003

[44] Taylor, R.C., Cullen, S.P. and Martin, S.J. (2008) Apoptosis Controlled Demolition at the Cellular Level. Nature Reviews Molecular Cell Biology, 9, 231-241. http://dx.doi.org/10.1038/nrm2312

[45] Reed, J.C. (1999) Bcl-2 Family Proteins. In: Hickman, J.A. and Dive, C., Eds., Apoptosis and Cancer Chemotherapy, Humana Press, Totowa, 99-116.

[46] Koike, T., Yang, Y., Suzuki, K. and Zheng, X. (2008) Axon and Dendrite Degeneration: Its Mechanisms and Protective Experimental Paradigms. Neurochemistry International, 52, 751-760. http://dx.doi.org/10.1016/j.neuint.2007.09.007

[47] Lu, R., Yang, D., Cui, D., Wang, Z. and Guo, L. (2012) Egg White-Mediated Green Synthesis of Silver Nanoparticles with Excellent Biocompatibility and Enhanced Radiation Effects on Cancer Cells. International Journal of Nanomedicine, 7, 2101-2107. http://dx.doi.org/10.2147/IJN.S29762

[48] Ma, J., Xu, R., Sun, J., Zhao, D., Tong, J. and Sun, X. (2013) Nanoparticle Surface and Nanocore Properties Determine the Effect on Radiosensitivity of Cancer Cells upon Ionizing Radiation Treatment. Journal of Nanoscience and Nanotechnology, 13, 1472-1475. http://dx.doi.org/10.1166/jnn.2013.6087

[49] Sanpui, P., Chattopadhyay, A. and Ghosh, S.S. (2011) Induction of Apoptosis in Cancer Cells at Low Silver Nanoparticle Concentrations Using Chitosan Nanocarrier. ACS Applied Materials and Interfaces, 3, 218-228. http://dx.doi.org/10.1021/am100840c

[50] Su, X.Y., Liu, P.D., Wu, H. and Gu, N. (2014) Enhancement of Radiosensitization by Metal-Based Nanoparticles in Cancer Radiation Therapy. Cancer Biology \& Medicine, 11, 86-91.

[51] Azarova, A.M., Lyu, Y.L., Lin, C.P., Tsai, Y.C., Lau, J.Y.N., Wang, J.C. and Liu, L.F. (2007) From the Cover Roles of DNA Topoisomerase II Isozymes in Chemotherapy and Secondary malignancies. Proceedings of the National Academy of Sciences of the United States of America, 104, 11014-11019. http://dx.doi.org/10.1073/pnas.0704002104 